Board of Governors of the Federal Reserve System

International Finance Discussion Papers

Number 650

October 1999

LONG MEMORY IN EMERGING MARKET STOCK RETURNS

Jonathan H. Wright

NOTE: International Finance Discussion Papers are preliminary materials circulated to stimulate discussion and critical comment. References in publications to International Finance Discussion Papers (other than an acknowledgment that the writer has had access to unpublished material) should be cleared with the author or authors. Recent IFDPs are available on the Web at www.bog.frb.fed.us. 


\title{
LONG MEMORY IN EMERGING MARKET STOCK RETURNS
}

\author{
Jonathan H. Wright*
}

\begin{abstract}
Many authors have investigated the possibility of long memory in asset returns. Generally, very little evidence has been found for long memory in either stock returns or exchange rate returns. This paper applies the log-periodogram regression to a wide range of emerging market stock returns and finds some evidence for positive long memory in 7 of the 17 series considered.
\end{abstract}

Keywords: Long Memory, Stock Returns, Frequency Domain, Emerging Markets.

* Wright is an economist in the International Finance Division of the Federal Reserve Board. I am grateful to Dan Jubinski and James Weston for helpful comments. All errors are my sole responsibility. 


\section{Introduction.}

Long memory in asset returns has potentially important implications for asset pricing models (see e.g. Greene and Fielitz (1979)). Potentially, a correct finding of long memory could be used to construct a profitable trading strategy. Long memory implies that perfect arbitrage is impossible (Mandelbrot (1971)) and invalidates standard derivative pricing models based on Brownian motion and martingale assumptions.

Consequently, many authors have tested for long memory in asset returns, including both stock and exchange rate returns. Lo (1991) proposed robustifying the rescaled range statistic of Hurst (1951) against short run dependence. He applied his modified rescaled range statistic to the returns on some U.S. stock indices. Jacobsen (1996) tested for long memory in U.S., Japanese and some West European stock index returns. Cheung (1993a) tested for long memory in exchange rate returns, while Hiemstra and Jones (1997) considered long memory in U.S. individual stock returns. Crato (1994) and Cheung and Lai (1995) both test for long memory in stock return indices for a number of developed markets. Naturally, this is only a partial listing of the papers which have studied long memory in financial asset returns. However, broadly speaking, these papers (and the many other papers in this area) find little evidence for long memory in asset returns. Other authors have found strong evidence

for long memory in the squared, log-squared or absolute values of asset returns (see e.g. Ding et al. (1993), Breidt et al. (1998), Harvey (1998) and Lobato and Savin 
(1998)). This paper however does not deal with these long memory volatility dependencies, focussing exclusively on the search for long memory in the levels of asset returns. Indeed, some authors have not even been able to reject the null hypothesis that some asset returns form a martingale difference sequence (e.g. Liu and He (1991) for exchange rate returns). Consequently, it is not clear that there is any serial correlation whatsoever in these series. One interesting exception, however, is Barkoulas, Baum and Travlos (1999), who report some evidence for long memory in the Greek stock market, suggesting that the search for long memory may be more fruitful in the context of smaller and less developed stock markets.

Notwithstanding their high risk, emerging markets are of great interest to investors, both for reasons of portfolio diversification (because of their low correlation with developed market returns) and because of their potential profitability. This paper is concerned with testing for long memory in returns for a wide range of emerging market stock return indices. A number of authors, including Bekaert (1995), Bekaert and Harvey (1995) and Harvey (1995a,b) have noted that emerging market returns tend to be more persistent than those in more developed markets. The sample autocorrelations of emerging market returns are often statistically significant, as discussed in these papers. This could represent some market inefficiency, which could be exploited by investors to earn excess returns, even after controlling for risk. It could be because the risk factors are more persistent in emerging markets. Potentially, it could 
simply reflect a lack of liquidity in emerging markets, though Harvey (1995b) argues against this potential explanation. The goal of the present paper is to investigate whether or not this persistence in emerging market returns actually takes the form of long memory.

The plan of the remainder of this paper is as follows. The concepts of long memory and fractional integration, as well as the methods for estimating and testing for fractional integration are introduced in section 2. The empirical work is described in section 3. Section 4 concludes.

\section{Long Memory Models.}

Many time series, both in economics and in other fields, have autocorrelation functions which appear to decay slowly. These series also appear to have power spectra which are unbounded at the origin, a property which Granger (1966) referred to as the

"typical spectral shape" of an economic variable. These properties imply that a shock to the time series is very long lasting. They are the key characteristics of a long memory time series.

More formally, I define a time series as being long memory if it has an autocovariance function $\gamma(j)$ and a power spectrum $f(\lambda)$ such that

$$
\gamma(j)^{\sim} j^{2 H-2}
$$


as $j \rightarrow \infty$ and

$$
f(\lambda)^{\sim} \lambda^{1-2 H}
$$

as $\lambda \rightarrow 0$, for $H \in(0,1), H \neq \frac{1}{2}$, where the ${ }^{\sim}$ notation means that the limit of the ratio of the quantities on the left and right hand sides of the symbol is a finite positive constant. If the self-similarity parameter $H$ is greater than $\frac{1}{2}$, the spectrum is unbounded at the origin (positive long memory). If $H$ is less than $\frac{1}{2}$, then $f(0)=0$ (negative long memory, or antipersistence).

\subsection{Fractional Integration and the ARFIMA Model.}

The ARFIMA model is the leading long memory time series model. Let $U_{t}$ be an $\operatorname{ARMA}(p, q)$ time series, with $p$ and $q$ both finite, with autoregressive and moving average lag polynomials having all their roots outside the unit circle. Let $X_{t}$ be a time series such that $(1-L)^{d} X_{t}=U_{t}$, for $d \in\left(-\frac{1}{2}, \frac{1}{2}\right)$, where the fractional differencing operator is defined by the usual binomial series expansion, i.e.

$$
(1-L)^{d}=1-d L+\frac{d(d-1)}{2} L^{2} \ldots
$$

and $L$ is the lag operator. The time series $X_{t}$ is then said to be a fractionally integrated series, or an $\operatorname{ARFIMA}(\mathrm{p}, \mathrm{d}, \mathrm{q})$ series $^{1}$. For the given range of $d$, it is both stationary

\footnotetext{
${ }^{1}$ In this paper I define fractional integration to be synonymous with an ARFIMA model, though it is possible to define fractional integration a little more generally.
} 
and invertible ${ }^{2}$. The ARFIMA time series can be shown to satisfy equations 2.1 and 2.2 with $d=H-\frac{1}{2}$. The concept of fractional integration was first developed in hydrology, but was introduced to econometrics by a number of authors, including Granger and Joyeux (1980). Recent comprehensive surveys of fractional integration and other long memory models include Robinson (1994) and Baillie (1996).

\subsection{Inference on $d$.}

There are two types of estimators of $d$ in the literature on fractional integration: parametric estimators, which estimate $d$ and all the other ARFIMA parameters jointly and semiparametric estimators, which estimate just $d$ without specifying the shortrun dynamics ${ }^{3}$. The parametric estimators typically involve maximizing the Gaussian log-likelihood, or some approximation to it. The most common semiparametric estimator is the log-periodogram regression estimator. This estimator was first proposed by Geweke and Porter-Hudak (1983). However a proof of its consistency and limiting distribution were elusive until Robinson (1995) provided these, in the case of a Gaussian time series.

The idea underlying this method is that the spectrum of a fractionally integrated time series is approximately log-linear for frequencies close to zero with a

\footnotetext{
${ }^{2}$ It is not necessary to restrict $d$ to lie between $-\frac{1}{2}$ and $\frac{1}{2}$, but then $X_{t}$ will be nonstationary (for $d>\frac{1}{2}$ ) or noninvertible (for $d<-\frac{1}{2}$ ).

${ }^{3}$ Semiparametric methods may also be used in the estimation of the parameter $H$ of a general long-memory time series.
} 
slope equal to $-2 d$. Specifically, let $I(\lambda)$ denote the sample periodogram of $X_{t}$. The $\log$-periodogram regression estimate of $d$, or $\hat{d}$, is then given by minus the estimate of $\beta_{1}$ in the regression equation

$$
\log \left(I\left(\lambda_{j}\right)\right)=\beta_{0}+\beta_{1} \log \left[4 \sin ^{2}\left(\lambda_{j} / 2\right)\right]+\zeta_{j}, j=1, \ldots m
$$

where $0<m<<T$, and $\lambda_{j}=2 \pi j / T$ denotes the jth Fourier frequency based on a sample of $T$ observations. The bandwidth parameter, $m$, must converge to infinity while $m / T \rightarrow 0$. The heuristic motivation for the estimator is clear since $4 \sin ^{2}(\lambda / 2) \simeq \lambda^{2}$ for $\lambda$ close to zero, and $f(\lambda) \backsim \lambda^{-2 d}$ as $\lambda \rightarrow 0$. In the case of a Gaussian fractionally integrated series, Robinson (1995) proved that $\hat{d}$ was consistent and that

$$
\sqrt{2 m}(\hat{d}-d) \rightarrow{ }_{d} N\left(0, \frac{\pi^{2}}{6}\right)
$$

Robinson's proof requires some of the lowest frequencies to be omitted from the logperiodogram regression, though this is not usually done in empirical applications. Besides Hurvich, Deo and Brodsky (1998) have extended Robinson's proof to the case where there is no such trimming of the lowest frequencies. Often there is particular interest in testing the null hypothesis of no fractional integration $\left(H_{0}: d=0\right)$. Clearly the t-statistic $\hat{d} / \sqrt{\frac{\pi^{2}}{24 m}}$ can be used to test this hypothesis and will be asymptotically standard normal (in the Gaussian fractionally integrated case) under the 
null $^{4}$. Henceforth in this paper, I refer to this as the GPH test.

Other alternative tests of the null of no fractional integration are available. One widely used test uses the rescaled range statistic (first proposed by Hurst (1951)), as modified by Lo (1991) to allow for short run dependence under the null ${ }^{5}$. Cheung (1993b) evaluates the power of a number of tests for fractional integration and finds that the modified rescaled range test can have much less small sample power against positive fractional integration than the GPH test. For instance, in an $\operatorname{ARFIMA}(0, \mathrm{~d}, 0)$ model with $d=0.45$ (considerable positive fractional integration), with a sample size of 300, Cheung finds that the rejection probability of the modified rescaled range test is only $22.7 \%$, while the GPH test rejects with probability $66.8 \%$. Parametric likelihood based tests are of course available (Baillie (1996)). These are likely to be more powerful, but do not allow the researcher to test for fractional integration while remaining agnostic about the short run dynamics. Accordingly, in this paper, I follow much of the applied literature on fractional integration (e.g. Cheung (1993a), Diebold and Rudebusch (1993)) by focussing exclusively on the GPH test.

\footnotetext{
${ }^{4}$ Alternatively, the denominator in this t-statistic could be replaced by the usual OLS standard error (Robinson (1995)).

${ }^{5}$ This test is also semiparametric, as it does not require a particular model of the short run dynamics to be specified and estimated.
} 


\section{Empirical Work.}

\subsection{The Data.}

The data on emerging markets used in this paper consists of the total (dividendinclusive) U.S. dollar returns for 17 International Financial Corporation (IFC) national stock market indices. The 17 countries are Argentina, Brazil, Chile, Colombia, Greece, India, Jordan, Korea, Malaysia, Mexico, Nigeria, Pakistan, Philippines, Taiwan, Thailand, Venezuela and Zimbabwe. I consider the returns in U.S. dollars because this is presumably most relevant for international investors and because local currency returns are very erratic because of occasional bursts of hyperinflation, especially in Argentina and Brazil. Bekaert (1995), Bekaert and Harvey (1995) and Harvey (1995a,b), in their studies of emerging market returns, likewise focus on total U.S. dollar monthly returns on the IFC indices. The data is monthly (based on end-month stock price indices) covering the period December 1975-September 1998, although the data starts later for some countries ${ }^{6}$.

For each of these indices, the sample period, sample size, sample mean of returns and sample standard deviation of returns are all reported in Table 1. The average returns for many emerging markets, especially the East Asian markets, are much

\footnotetext{
${ }^{6}$ Each of these 17 countries satisfied the World Bank definition of a developing economy at the start of the sample, though some of these countries (such as Greece and Korea) would no longer be considered to be developing, by the World Bank criterion.
} 
lower than reported in earlier papers, such as Bekaert (1995), because more recent data is included in the present paper. The average returns in the emerging markets range from $1.5 \%$ (Malaysia) to $27.1 \%$ (Columbia). As is well known, the emerging market returns are highly volatile. Some emerging market returns have a variance that is nearly 10 times that of U.S. stock market returns.

\subsection{The Log-Periodogram Regression Results.}

I use the log-periodogram regression to estimate $d$ and to test the hypothesis that $d=0$ for the stock returns in each of the 17 emerging markets. Following Cheung (1993b) and many other authors, I adopt the convention of setting the bandwidth equal to the square root of the sample size, rounded off to the nearest integer. I refer to this as the baseline case; some sensitivity analysis is conducted below. For those countries for which data is available back to December 1975, this corresponds to $m=17$.

The results are reported in Table 2 . The point estimates of $d$ are positive for 15 of the 17 countries, being slightly (and insignificantly) below zero for just Argentina and India. The estimates of $d$ are significantly positive at the $1 \%$ level for 3 markets (Chile, Philippines and Thailand), at the 5\% level for 3 markets (Columbia, Korea and Malaysia) and at the $10 \%$ level for Greece. There is thus some evidence for positive long memory in 7 of the 17 series of emerging market returns. For the Greek stock returns, the estimate of $d$ is 0.28 with a t-statistic of 1.79 . This is quite close 
to the results obtained by Barkoulas, Baum and Travlos (1999), for weekly returns on an index of 30 heavily traded stocks on the Athens Stock Exchange ${ }^{7}$.

\subsection{Sensitivity Analysis.}

The results reported above all set the bandwidth $m$ to the square root of the sample size, $T$, rounded off to the nearest integer. In this subsection, I investigate the results with alternative, less standard, bandwidths. The bandwidths which I consider are $m=T^{\alpha}$, rounded off to the nearest integer, for $\alpha=0.4,0.45,0.55,0.6$. For those countries for which data is available back to December 1975, this corresponds to $m$ ranging between 9 and 29; accordingly $\alpha=0.4$ or 0.45 corresponds to an extremely small number of observations in the log periodogram regression. This is especially true in those countries for which the data has a later starting date. Nevertheless, the results for all these bandwidths are reported in Table 3. Considerable sensitivity with respect to the bandwidth choice can be found. This sensitivity is a well known problem with the practical implementation of the log-periodogram regression (see, for example Geweke (1998)).

However, for all bandwidth choices, most of the point estimates of $d$ are positive.

For the 7 markets in which I found significant long memory in the baseline case $(\alpha=0.5)$, the point estimates remain positive for all bandwidth choices, but may or

\footnotetext{
${ }^{7}$ For a bandwidth equal to the square root of the sample size, Barkoulas, Baum and Travlos (1999) did not find that $\hat{d}$ was significant, even at the $10 \%$ level. They did find $\hat{d}$ to be significant for some other (less standard) bandwidth choices.
} 
may not remain significant. The most robust evidence for long memory arises in the case of three East Asian markets: Korea, the Philippines and Thailand (significant, at least at the $10 \%$ level for all bandwidths, or all but one bandwidth). The evidence for long memory, found in the baseline case for Chile and Colombia, is robust to increasing the bandwidth (but not to reducing it). The results are least robust for Malaysia and Greece; for these markets, there is only one other bandwidth for which the long memory is significant. Some markets, notably Zimbabwe, have significant positive long memory at some of these alternative bandwidths, but not in the baseline case.

\subsection{Discussion of the Results.}

I do not argue that the results of subsections 3.2 and 3.3 constitute overwhelming evidence for long memory dependencies in emerging market returns. Nevertheless, it contrasts quite sharply with most of the studies of long memory in the levels of asset returns which have generally found no evidence whatsoever for long memory. The fact that 15 of the 17 point estimates are positive, while 7 are significantly positive, with the standard baseline bandwidth choice, indicates that fractional integration may be a useful way of thinking about the serial correlation properties of these returns ${ }^{8}$. This

\footnotetext{
${ }^{\gamma}$ Bekaert and Harvey (1995) provide measures of the degree of integration of emerging markets into world capital markets, for a subset of the emerging markets that I have considered in this paper. There is no apparent relationship between the estimated long memory parameters and these measures of market integration.
} 
is especially true in the light of the power of the available tests and the relatively short span of data which exists on emerging market returns.

\section{Conclusion.}

Emerging market returns appear to have considerable serial correlation. In emerging markets, it is often possible to predict future returns, using only lagged returns (e.g. Bekaert (1995)). This stands in contrast to the results for the United States and other similar markets, where there is little evidence for any serial correlation in stock returns (let alone long memory) and where lagged returns have little predictive power for future returns. In this paper, I have tested for long memory in emerging market returns and have found some evidence for positive long memory in 7 of the 17 series that I considered. 


\section{References.}

Andrews, D.W.K. (1991): Heteroskedasticity and Autocorrelation Consistent Covariance Matrix Estimation, Econometrica, 59, pp.817-858.

Baillie, R.T. (1996): Long Memory Processes and Fractional Integration in Econometrics, Journal of Econometrics, 73, pp.5-59.

Barkoulas, J.T., C.F. Baum and N. Travlos (1999): Long Memory in the Greek Stock Market, Applied Financial Economics, forthcoming.

Bekaert, G. (1995): Market Integration and Investment Barriers in Emerging Equity Markets, World Bank Economic Review, 9, pp.75-107.

Bekaert, G. and C.R. Harvey (1995): Time-Varying World Market Integration, Journal of Finance, 50, pp.403-444.

Breidt, F.J., N. Crato and P. de Lima (1998): The Detection and Estimation of Long Memory in Stochastic Volatility, Journal of Econometrics, 83, pp.325-348.

Cheung, Y.W. (1993a): Long Memory in Foreign Exchange Rates, Journal of Business and Economic Statistics, 11, pp.93-101.

Cheung, Y.W. (1993b): Tests for Fractional Integration: A Monte Carlo Investigation, Journal of Time Series Analysis, 14, pp.331-345.

Ding, Z., C.W.J. Granger and R.F. Engle (1993): A Long Memory Property of Stock Returns and a New Model, Journal of Empirical Finance, 1, pp.83-106.

Geweke, J. and S. Porter-Hudak (1983): The Estimation and Application of Long- 
Memory Time Series Models, Journal of Time Series Analysis, 4, pp.221-237

Geweke, J. (1998): Comment on Real and Spurious Long-Memory Properties of Stock-

Market Data (by I.N. Lobato and N.E. Savin), Journal of Business and Economic Statistics, 16, pp.269-271.

Granger, C.W.J. (1966): The Typical Spectral Shape of an Economic Variable, Econometrica, 34, pp.150-161.

Granger, C.W.J. and R. Joyeux (1980): An Introduction to Long-Memory Time Series Models and Fractional Differencing, Journal of Time Series Analysis, 1, pp.15-29.

Greene, M.T. and B.D. Fielitz (1979): The Effect of Long Term Dependence on RiskReturn Models of Common Stocks, Operations Research, 27, pp.944-951.

Harvey, A.C. (1998): Long-Memory in Stochastic Volatility, in Forecasting Volatility in Financial Markets, (eds. J. Knight and S. Satchell), Butterworth-Heineman, London.

Harvey, C.R. (1995a): Predictable Risk and Returns in Emerging Markets, Review of Financial Studies, 8, pp.773-816.

Harvey, C.R. (1995b): The Risk Exposure of Emerging Equity Markets, World Bank Economic Review, 9, pp.19-50.

Hiemstra, C. and J.D. Jones (1997): Another Look at Long Memory in Common Stock Returns, Journal of Empirical Finance, 4, pp.373-401.

Hurst, H. (1951): Long Term Storage Capacity of Reservoirs, Transactions of the 
American Society of Civil Engineers, 116, pp.770-799.

Hurvich, C.M., R. Deo and J. Brodsky (1998): The Mean Square Error of Geweke and Porter-Hudak's Estimator of the Memory Parameter of a Long Memory Time Series, Journal of Time Series Analysis, 19, pp.19-46.

Jacobsen, B. (1996): Long-Term Dependence in Stock Returns, Journal of Empirical Finance, 3, pp.393-417.

Liu, C.Y. and J. He (1991): A Variance Ratio Test of Random Walks in Foreign Exchange Rates, Journal of Finance, 46, pp.773-785.

Lo, A. (1991): Long-Term Memory in Stock Market Prices, Econometrica, 59, pp.12791313.

Lobato, I and N.E. Savin (1998): Real and Spurious Long-Memory Properties of Stock-Market Data, Journal of Business and Economic Statistics, 16, pp.261-268. Mandelbrot, B. (1971): When Can Price Be Arbitraged Efficiently? A Limit to the Validity of the Random Walk and Martingale Models, Review of Economics and Statistics, 53, pp.225-236.

Robinson, P.M. (1994): Time Series with Strong Dependence, in "Advances in Econometrics, Sixth World Congress" (C.A. Sims, ed.). Cambridge University Press. 
Table 1. Summary Statistics for Stock Index Returns

\begin{tabular}{llllll}
\hline Market & Starting Date & Ending Date & Sample Size & Mean (\%) & Standard Deviation (\%) \\
& & & & & \\
\hline Argentina & $1975: 12$ & $1998: 9$ & 273 & 14.6 & 73.7 \\
Brazil & $1975: 12$ & $1998: 9$ & 273 & 9.5 & 52.4 \\
Chile & $1975: 12$ & $1998: 9$ & 273 & 23.1 & 49.5 \\
Colombia & $1984: 12$ & $1998: 9$ & 165 & 27.1 & 42.4 \\
Greece & $1975: 12$ & $1998: 9$ & 273 & 5.6 & 41.1 \\
India & $1975: 12$ & $1998: 9$ & 273 & 11.4 & 27.8 \\
Jordan & $1978: 1$ & $1998: 9$ & 248 & 9.4 & 17.7 \\
Korea & $1975: 12$ & $1998: 9$ & 273 & 6.5 & 40.2 \\
Malaysia & $1984: 12$ & $1998: 9$ & 165 & 1.5 & 42.4 \\
Mexico & $1975: 12$ & $1998: 9$ & 273 & 14.9 & 55.9 \\
Nigeria & $1984: 12$ & $1998: 9$ & 165 & 4.6 & 47.9 \\
Pakistan & $1984: 12$ & $1998: 9$ & 165 & 8.6 & 32.3 \\
Philippines & $1984: 12$ & $1998: 9$ & 165 & 21.1 & 57.0 \\
Taiwan & $1984: 12$ & $1998: 9$ & 165 & 18.3 & 49.1 \\
Thailand & $1975: 12$ & $1998: 9$ & 273 & 8.6 & 44.1 \\
Venezuela & $1984: 12$ & $1998: 9$ & 165 & 11.5 & 62.5 \\
Zimbabwe & $1975: 12$ & $1998: 9$ & 273 & 6.7 & 57.9 \\
& & & & & \\
\hline
\end{tabular}


Table 2. Log-Periodogram Regression Results for Stock Index Returns with Bandwidth $\mathbf{m}=\mathbf{T}^{0.5}$

\begin{tabular}{llll}
\hline Market & $\mathbf{m}$ & Estimated $\mathbf{d}$ & t-statistic \\
& & & \\
\hline Argentina & 17 & -0.05 & -0.32 \\
Brazil & 17 & 0.03 & 0.22 \\
Chile & 17 & $0.54^{* * *}$ & 3.49 \\
Colombia & 13 & $0.36^{* *}$ & 2.00 \\
Greece & 17 & $0.28^{*}$ & 1.79 \\
India & 17 & -0.09 & -0.56 \\
Jordan & 16 & 0.06 & 0.35 \\
Korea & 17 & $0.33^{* *}$ & 2.10 \\
Malaysia & 13 & $0.35^{* *}$ & 1.97 \\
Mexico & 17 & 0.16 & 1.05 \\
Nigeria & 13 & 0.03 & 0.15 \\
Pakistan & 13 & 0.26 & 1.45 \\
Philippines & 13 & $0.51^{* * *}$ & 2.89 \\
Taiwan & 13 & 0.12 & 0.66 \\
Thailand & 17 & $0.63^{* * *}$ & 4.05 \\
Venezuela & 13 & 0.26 & 1.45 \\
Zimbabwe & 17 & 0.22 & 1.39 \\
& & & \\
\hline
\end{tabular}

Note: ${ }^{*},{ }^{* *}$ and ${ }^{* * *}$ superscripts denote significance at the $10 \%, 5 \%$ and $1 \%$ levels, respectively. 
Table 3. Sensitivity Analysis: Log-Periodogram Estimates of d (t-statistics) for Alternative Bandwidth Choices

\begin{tabular}{|c|c|c|c|c|}
\hline Market & $\mathbf{m}=\mathbf{T}^{0.4}$ & $\mathbf{m}=\mathbf{T}^{0.45}$ & $\mathbf{m}=\mathbf{T}^{0.55}$ & $\mathbf{m}=\mathbf{T}^{0.6}$ \\
\hline Argentina & $\begin{array}{l}-0.35 \\
(-1.63)\end{array}$ & $\begin{array}{l}-0.30 \\
(-1.61)\end{array}$ & $\begin{array}{l}-0.01 \\
(-0.05)\end{array}$ & $\begin{array}{l}0.04 \\
(-0.30)\end{array}$ \\
\hline Brazil & $\begin{array}{l}-0.38^{*} \\
(-1.79)\end{array}$ & $\begin{array}{l}-0.34^{*} \\
(-1.85)\end{array}$ & $\begin{array}{l}0.10 \\
(0.72)\end{array}$ & $\begin{array}{l}-0.06 \\
(-0.48)\end{array}$ \\
\hline Chile & $\begin{array}{l}0.01 \\
(0.03)\end{array}$ & $\begin{array}{l}0.10 \\
(0.54)\end{array}$ & $\begin{array}{l}0.60^{* * *} \\
(4.35)\end{array}$ & $\begin{array}{l}0.20^{*} \\
(1.71)\end{array}$ \\
\hline Colombia & $\begin{array}{l}0.02 \\
(0.07)\end{array}$ & $\begin{array}{l}0.21 \\
(1.03)\end{array}$ & $\begin{array}{l}0.31^{* *} \\
(1.98)\end{array}$ & $\begin{array}{l}0.37^{* * *} \\
(2.66)\end{array}$ \\
\hline Greece & $\begin{array}{l}-0.07 \\
(-0.34)\end{array}$ & $\begin{array}{l}0.20 \\
(1.06)\end{array}$ & $\begin{array}{l}0.35^{* *} \\
(2.53)\end{array}$ & $\begin{array}{l}0.15 \\
(1.26)\end{array}$ \\
\hline India & $\begin{array}{l}-0.26 \\
(-1.20)\end{array}$ & $\begin{array}{l}-0.30 \\
(-1.60)\end{array}$ & $\begin{array}{l}0.08 \\
(0.57)\end{array}$ & $\begin{array}{l}0.00 \\
(-0.03)\end{array}$ \\
\hline Jordan & $\begin{array}{l}0.23 \\
(1.09)\end{array}$ & $\begin{array}{l}-0.02 \\
(-0.11)\end{array}$ & $\begin{array}{l}0.09 \\
(0.66)\end{array}$ & $\begin{array}{l}0.09 \\
(0.76)\end{array}$ \\
\hline Korea & $\begin{array}{l}0.32 \\
(1.49)\end{array}$ & $\begin{array}{l}0.37^{* *} \\
(2.01)\end{array}$ & $\begin{array}{l}0.58^{* * *} \\
(4.25)\end{array}$ & $\begin{array}{l}0.34^{* * *} \\
(2.86)\end{array}$ \\
\hline Malaysia & $\begin{array}{l}0.24 \\
(1.05)\end{array}$ & $\begin{array}{l}0.35^{*} \\
(1.73)\end{array}$ & $\begin{array}{l}0.14 \\
(0.88)\end{array}$ & $\begin{array}{l}0.02 \\
(0.17)\end{array}$ \\
\hline Mexico & $\begin{array}{l}-0.02 \\
(-0.08)\end{array}$ & $\begin{array}{l}0.17 \\
(0.91)\end{array}$ & $\begin{array}{l}0.22 \\
(1.62)\end{array}$ & $\begin{array}{l}0.11 \\
(0.90)\end{array}$ \\
\hline Nigeria & $\begin{array}{l}0.05 \\
(0.21)\end{array}$ & $\begin{array}{l}-0.06 \\
(-0.32)\end{array}$ & $\begin{array}{l}0.04 \\
(0.29)\end{array}$ & $\begin{array}{l}-0.11 \\
(-0.75)\end{array}$ \\
\hline Pakistan & $\begin{array}{l}-0.06 \\
(-0.28)\end{array}$ & $\begin{array}{l}0.03 \\
(0.15)\end{array}$ & $\begin{array}{l}0.11^{*} \\
(1.74)\end{array}$ & $\begin{array}{l}0.12 \\
(0.86)\end{array}$ \\
\hline Philippines & $\begin{array}{l}1.00^{* * *} \\
(4.39)\end{array}$ & $\begin{array}{l}0.69^{* *} \\
(3.43)\end{array}$ & $\begin{array}{l}0.25^{*} \\
(1.63)\end{array}$ & $\begin{array}{l}0.21 \\
(1.50)\end{array}$ \\
\hline Taiwan & $\begin{array}{l}0.15 \\
(0.64)\end{array}$ & $\begin{array}{l}0.19 \\
(0.93)\end{array}$ & $\begin{array}{l}-0.05 \\
(-0.35)\end{array}$ & $\begin{array}{l}0.08 \\
(0.59)\end{array}$ \\
\hline Thailand & $\begin{array}{l}0.86^{* * *} \\
(4.01)\end{array}$ & $\begin{array}{l}0.74^{* * *} \\
(3.98)\end{array}$ & $\begin{array}{l}0.52^{* * *} \\
(3.84)\end{array}$ & $\begin{array}{l}0.20^{*} \\
(1.69)\end{array}$ \\
\hline Venezuela & $\begin{array}{l}0.14 \\
(0.60)\end{array}$ & $\begin{array}{l}0.10 \\
(0.50)\end{array}$ & $\begin{array}{l}0.26^{*} \\
(1.68)\end{array}$ & $\begin{array}{l}0.09 \\
(0.65)\end{array}$ \\
\hline Zimbabwe & $\begin{array}{l}-0.03 \\
(-0.12)\end{array}$ & $\begin{array}{l}0.36^{*} \\
(1.93)\end{array}$ & $\begin{array}{l}0.34^{* *} \\
(2.46)\end{array}$ & $\begin{array}{l}0.32^{* * *} \\
(2.72)\end{array}$ \\
\hline
\end{tabular}

Note: $*{ }^{* *}$ and ${ }^{* * *}$ superscripts denote significance at the $10 \%, 5 \%$ and $1 \%$ levels, respectively. 